\title{
O papel da sexualidade na família moderna, frente aos valores cristãos
}

\author{
The role of sexuality in the modern Family, facing christian \\ values
}

Alison Humberto Furlan

\section{Resumo}

O corpo alheio é um obstáculo ou uma ponte; é preciso ultrapassá-lo. Só se deve ultrapassar pelo amor ao outro, criando assim, relações saudáveis. Verifica-se que o cristianismo busca, porém, não de forma homogênea, orientar seus fiéis e a sociedade em geral nos aspectos de conflito entre fé cristã e a modernidade. Um destes conflitos se encontra na sexualidade que se acredita haver valores imprescindíveis. Analisando alguns escritores na área da sexualidade, bem como alguns documentos da tradição Católica Romana, busca-se discutir como a fé responde às questões de sexualidade e das uniões conjugais, e como a pastoral vem se atualizando aos sinais dos tempos, sem deixar de ser evangélica. Portanto, a sexualidade é um componente fundamental da personalidade, um modo de ser, de se manifestar, de se comunicar com os outros, de sentir, de expressar, de viver o amor humano e realizar o próprio sentido de existir; deve ser integrada e, acima de tudo, vivida com maturidade e aceitação. Só assim teremos relações mais sadias, que ajudem na construção de uma sociedade mais justa, e que desenvolva uma pastoral familiar mais inclusiva, integrando os fiéis nas comunidades cristãs.

Palavras-chave: Afetividade. Sexualidade. Matrimônio. Configurações familiares.

\section{Abstract}

The other's body is an obstacle or a bridge, it is necessary to overcome it. It must only go beyond the love of one another, thus creating affective 
relationships. It is checked that Christianity seeks, however, not in a homogeneous way, to guide its faithful people and society in general in the aspects of conflict between Christian faith and modernity. One of these conflicts is found in sexuality, which is believed to have essential values. Analyzing some writers in the area of sexuality, as well as some documents from the Roman Catholic tradition, it seeks to discuss how faith responds to questions of sexuality and conjugal unions, and how pastoral care has been updated with the signs of the times, still being evangelical. Therefore, sexuality is a fundamental component of personality, a way of being, of manifesting, of communicating with others, of feeling, of expressing, of living human love and of realizing the very meaning of existing, it must be integrated and, above all, lived with maturity and acceptance. Only in this way will we have healthier relationships that help to build a more just society, and that develop a more inclusive family ministry, integrating the faithful people into Christian communities.

Keywords: Affectivity. Sexuality. Marriage. Family settings.

\section{Introdução}

Somos profundamente afetados por nossa sexualidade; ela é o fator que nos confere e dinamiza a vida. "Cada época, segundo Heidegger, tem uma coisa a pensar. Só uma. A do nosso tempo é a diferença sexual". "Vivemos uma cultura de exaltação do sexo, que está invadindo o campo da educação e modificando o modo de pensar das pessoas, que muitas vezes não sabem como lidar com as novidades que surgem.

$\mathrm{O}$ homem e a mulher vivem e experimentam sua sexualidade no plano psíquico com características diferenciais. Segundo Vidal, ${ }^{2}$ "Podemos dizer que o amor é masculino e feminino". A diferente anatomia do homem e da mulher tem suas repercussões no plano psíquico. Na espécie humana existe uma bipolaridade sexual em todos os níveis e em todos os espaços. Neste trabalho se analisa alguns modelos de família, que buscam, numa vida em sociedade a felicidade; além de haver a percepção de que existem diferentes formas de amar.

O que denominamos matrimônio constitui uma realidade evidentemente complexa, que reduz a perspectiva sexual ao âmbito da união conjugal. Com

\footnotetext{
${ }^{1}$ LACROIX, X., Introdução, p. 8.

${ }^{2}$ VIDAL, M., Ética da sexualidade, p. 20.
} 
efeito, pode-se definir o casal conjugal como forma de relação humana baseada no amor, de amizade heterossexual que constitui um grupo afetivo, uma família.

Ao se observar a história, percebemos que muitas pessoas viveram frustradas, infelizes e de certa forma, "assexuadas". Na raiz Católica do cristianismo se adotou a castidade, a fim de se evitar o corpo, o toque, o sexo. O iluminismo (início do século XX) despertou na humanidade a independência pessoal, e assim surgiram movimentos, como o feminismo, que iniciaram a transformação social. Através dos meios de comunicação em massa e fatores, tais como, o aumento da expectativa de vida, desenvolveu-se uma nova visão da sexualidade. Vidal assim descreve:

Sempre existiram comportamentos contrários à norma vigente. Com maior ou menor abundância, sempre ocorreram relações sexuais extraconjugais. Nesse sentido nossa situação atual não é melhor nem pior que outras situações históricas passadas. Entretanto, o radicalmente novo da situação presente é a "intencionalidade" significativa com que esses comportamentos se apresentam. ${ }^{3}$

Não surge apenas a independência da pessoa em relação às instituições, ocorrem também problemas para a sociedade. Antes, estava-se de um lado do pêndulo, agora se está no outro: da proibição ao liberalismo total; não se sabe o que fazer com tanta liberdade, com o corpo, como chamar a atenção para se realizar, gerando vários tipos de problemas sociais: desde grandes números de estupros até depressões profundas. A Igreja Católica na Declaração Persona Humana, sobre a ética sexual, expõe essa situação:

Nestes últimos tempos, aumentou a corrupção dos costumes de que é um dos mais graves índices uma desmesurada exaltação do sexo; ao mesmo tempo, pela difusão dos meios de comunicação social e dos espetáculos, ela tem vindo a invadir o campo da educação e a infectar a mentalidade geral. ${ }^{4}$

A doutrina cristã eleva sua voz em defesa da perenidade da união conjugal, como alicerce da estabilidade da família. O amor na união conjugal alcança seu ápice no matrimônio, reflexo da união indissolúvel de Cristo com sua Igreja. Mas é necessário ter um novo olhar para acolher os indivíduos que não têm uma família dentro desses padrões morais propostos e que professam a fé em Cristo.

${ }^{3}$ VIDAL, M., Ética da sexualidade, p.227.

${ }^{4} \mathrm{PH} 1$. 
Quer-se dar um olhar especial a este tema para redescobrir o valor do casamento, da sexualidade, afetividade e fidelidade, tudo o que este ato acarreta à vida cristã e na sociedade, que pretende ser a mais linda expressão do amor de Deus por seus filhos.

\section{Sexualidade: parte constituinte da humanidade}

A compreensão e a integração afetivo-sexual do ser humano tem mudado muito nos últimos anos. É preciso ter em mente a complexidade da realidade sexual e só se terá esta noção no momento em que se conceber o ser humano como um todo, como unidade, como pessoa humana. Não se pode separar como que em "gavetas" as dimensões humanas. Com isso:

É preciso afirmar a complexidade do fenômeno e da realidade do sexual. Mas toda essa complexidade é resolvida de maneira definitiva numa unidade: a pessoa humana. Essa é a dimensão fundamental da sexualidade. Colocada nessa perspectiva, podemos avaliar a altura, a longitude, a largura e a profundidade da sexualidade. Quatro dimensões no âmbito da única dimensão pessoal. ${ }^{5}$

A sexualidade, ao contrário do que muitas vezes vem à mente, não se reduz ao âmbito dos impulsos genitais. Segundo Vidal, ${ }^{6}$ "(há) uma ampliação do conceito de sexualidade, iniciada por Freud, e continuada por seus discípulos, e que é admitida por todos, psicólogos e sexólogos”. A sexualidade, portanto, abrange todas as dimensões constituintes do ser humano.

O ser humano é tão tocado pela sexualidade, que deve ser considerada como um dos fatores que caracterizam a vida de cada um dos indivíduos. Como nos apresenta a Congregação para a Doutrina da Fé: " "É do sexo que a pessoa recebe os caracteres que no plano biológico, psicológico e espiritual, os fazem homem e mulher, que são condicionados a tal realidade na sua consecução de maturidade e sua inserção na sociedade".

Chamados ao seguimento de Cristo, buscamos responder a Ele com audácia, e cientes do que nos constitui sexualmente:

O ser humano é chamado ao amor e ao dom de si na sua unidade corpóreo-espiritual. Feminilidade e masculinidade são dons

\footnotetext{
${ }^{5}$ VIDAL, M., Ética da sexualidade, p. 19.

${ }^{6}$ VIDAL, M., Ética da sexualidade, p. 20.

${ }^{7} \mathrm{PH} 1$.
} 
complementares, pelo que a sexualidade humana é parte integrante da capacidade concreta do amor que Deus inscreveu no homem e na mulher. A sexualidade é um comportamento fundamental da personalidade, um modo de ser, de manifestar, de se comunicar com os outros, de sentir, de expressar e de viver o amor humano. ${ }^{8}$

O ser humano retira da dimensão da sexualidade uma série de orientações para uma ética sexual saudável. O valor do comportamento sexual deve ser visto pelo ângulo pessoal, sabendo que a sexualidade possui sua essência voltada para a integração pessoal e interpessoal, da qual não se pode privar e, em muitos casos, reavaliar. É por meio da sexualidade que o ser humano chega ao outro, toca no outro, chega ao mais íntimo possível do universo que é o outro.

Como já visto, o ser humano deve ser integrado na dinâmica geral de sua sexualidade; esse é o princípio básico da ética sexual. Pode-se ver por dois ângulos este aspecto: será bom tudo o que favoreça e prepare e será mau tudo o que retarde, dificulte e mantenha a sexualidade num estado de imaturidade. Ainda:

A sexualidade de cada indivíduo tem seus aspectos próprios e irrepetíveis. Constitui uma peculiaridade intransferível. Entretanto, existe um esquema indefinido e genérico sobre o qual se constroem todas as sexualidades individuais. É esse esquema comum que se procura expor, mesmo admitindo tratar-se de um "esquema comum" e não de uma concreção perfeita da realidade. ${ }^{9}$

O ser humano tem que se conhecer e conhecer as diversas dimensões que o constituem. Ainda hoje criam-se e vivem-se sentimentos de culpa e de tabus, com base em concepções pré-científicas que não devem constituir o fundamento da ética sexual. A liberdade em abordar o tema afetivo sexual, na busca de plena clareza, é a melhor forma de se dialogar sobre este assunto.

A sexualidade transcende a relação sexual. Ela é uma energia motora que impulsiona o ser humano e dinamiza as suas relações consigo mesmo, com os outros, com a natureza e com o transcendente. É o lugar do desejo, do prazer e da responsabilidade.

Segundo Vidal, ${ }^{10}$ frente aos exageros de alguns psicólogos, é necessário afirmar: para chegar à maturidade sexual não é preciso ter experiências sexuais. Por essa razão muitas pessoas, casadas ou não, tem uma maturidade sexual

${ }^{8}$ CONSELHO PONTIFÍCIO PARA A FAMÍLIA, Sexualidade humana, 10.

${ }^{9}$ VIDAL, M., Ética da sexualidade, p. 63.

${ }^{10}$ VIDAL, M., Ética da sexualidade, p. 63. 
avançada, sem nunca ter tido relações sexuais, ou simplesmente a forma tradicional dela.

Segundo Brandão, ${ }^{11}$ Victor Frank nos ajuda a identificar três atitudes ou posturas que a pessoa pode assumir diante da vivência da afetividade e da sexualidade, que expressam diferentes níveis de amadurecimento pessoal. A atitude mais primária seria a que ele chama de atitude sexual. Essa atitude dirige-se ao corpo da outra pessoa, atraída por sua aparência física, baseia-se na atração instintiva por outra pessoa: o envolvimento com ela se dá pelo desejo e excitação sexual.

A segunda se dá na atitude erótica, que é aquilo que passa do desejo sexual, e se encontra na admiração pelo outro, no bem-estar emocional que o outro pode oferecer. O outro lhe atrai pelo que ele é e faz. Para Brandão: "É a atitude que possui um casal de namorados que estão apaixonados; a pessoa apaixonada está fascinada pela outra pessoa em sua totalidade, não só pelo seu corpo". ${ }^{12}$ Se a primeira atitude se encontra na parte corpórea, esta segunda se dá na corpórea e psicológica.

Junto a essas duas atitudes, a sexual e a erótica, surge também a atitude do amor, que se pode dizer é o ápice da maturidade sexual. E então, se une as dimensões corpórea e psicológica a dimensão espiritual:

A atitude do amor é a forma mais elevada possível do enamoramento, pois ela se dá quando nos dirigimos ao nível mais profundo da outra pessoa: quando prestamos atenção no que ela é enquanto pessoa, quando entramos em relação com o que ela tem de único e irrepetível. Quem vive a atitude do amor tem consciência de que ama o outro por aquilo que ele é, não apenas porque tem um corpo atraente ou por possuir determinada característica que apaixone, mas ama-o pelo que ele é em si mesmo. Quem ama é capaz de ver, através da "roupa" da aparência física e psíquica, a própria pessoa, para pôr os olhos nela própria: não se limita a amar o que quer que seja "no" ser amado, mas ama-o por si mesmo, pelo que ele "é", não pelo que ele "tem". Quem ama fica feliz pelo simples fato do amado existir. A atitude do amor, portanto, envolve as dimensões corpórea, psíquica e, particularmente, a dimensão espiritual. ${ }^{13}$

Para se conseguir o amadurecimento afetivo-sexual, portanto, é necessário chegar à atitude de amor. Essa é a meta do ser humano como ser

${ }^{11}$ BRANDÃO, S. R., Afetividade e sexualidade para o adolescente.

12 BRANDÃO, S. R., Afetividade e sexualidade para o adolescente.

${ }^{13}$ BRANDÃO, S. R., Afetividade e sexualidade para o adolescente. 
integrado, isto é, de descobrir e acolher o outro. Não alcançaremos a satisfação e felicidade nas relações se excluirmos estes aspectos, se vivermos esse desejo pela metade. "Esse amadurecimento não é apenas algo aconselhável ou indicado pelos especialistas, mas é uma exigência da pessoa, da sua natureza ou da sua ontologia, que apontam para essa unidade da pessoa". ${ }^{14}$

Neste processo rumo à maturidade afetivo-sexual, é de suma importância a dimensão biológica, pois é a partir das forças vitais das pulsões biológicas que acontece a realização humana. Ressalte-se novamente: é falho reduzir a dimensão da sexualidade à genitalidade. Se a sexualidade nos impõe posturas em relação a ela, para atingir sua plenitude, Vidal apresenta três significados da dimensão biológica para a compreensão da sexualidade humana: o procriativo, de luxo e o prazeroso.

No primeiro momento se descreve o significado procriativo da sexualidade. "Se não fosse mais que biologia sexual, a sexualidade humana não teria outro sentido senão o da procriação. Seria como fundamentalmente o é a sexualidade animal, uma sexualidade procriativa" ${ }^{15}$ Eis a primeira diferença da interação sexual na constituição da humanidade.

Num segundo momento, nos apresenta o significado de luxo da sexualidade. Pode ser considerado de luxo ou enriquecimento, pela superabundância de elementos fecundantes em relação aos elementos fecundados. "Pense nos milhões de espermatozoides que se perdem numa relação sexual que atinja a meta da fecundidade. A natureza nos oferece aqui um exemplo de esbanjamento biológico". ${ }^{16}$

Esse esclarecimento faz frente a uma moral que considera falha ética a perda de elementos fecundantes, como o espermatozoide, no ato sexual em que o objetivo não seja o da fecundação, pois até mesmo em uma relação sexual com o objetivo da fecundação muitos são os espermatozoides desperdiçados. Nossa sexualidade é composta por elementos abundantes, de grande importância e que podem ser desperdiçados, sendo assim, Vidal conclui que a falha ética deve ser colocada em outros níveis de consideração da sexualidade.

O terceiro significado apresentado é o prazeroso:

O significado prazeroso da sexualidade é vivido pelo homem no nível de todas as instâncias: o prazer do amor, da comunhão interpessoal, etc. É uma dimensão que se relaciona com todo o fenômeno da sexualidade

\footnotetext{
${ }^{14}$ BRANDÃO, S. R., Afetividade e sexualidade para o adolescente.

${ }^{15}$ VIDAL, M., Ética da sexualidade, p. 36.

16 VIDAL, M., Ética da sexualidade, p. 38.
} 
humana. Não obstante, cremos que esta dimensão lhe advém fundamentalmente da instância biológica. Por isso afirmamos que a dimensão prazerosa é um significado da instância biológica com referência à globalidade da sexualidade humana. ${ }^{17}$

A sexualidade humana deve ser vista na integridade do indivíduo ou do casal. Não precisa de desculpas para a sexualidade ser válida. Ela vai além dos atos, abrange os níveis psicológicos, espirituais e morais, de forma que o ser humano só será feliz se for um ser integrado nas suas dimensões.

\section{Corpos solidários}

Considerando os novos meios de pensar e viver a sexualidade na era da pósmodernidade, o mundo ocidental sente o desejo de busca, de conhecer melhor esta "nova" forma de experiência, na qual parece tudo ser permitido, em prol da realização pessoal e da felicidade, porém de realização e felicidade efêmeras.

Enquanto isso, o cristianismo tenta dar respostas para diminuir o impacto desse novo modo de ser e se põe a defender sua moral. Em alguns casos buscando a adequação que concilie Tradição e a abertura aos sinais dos tempos; mas, em outros casos, as mudanças são morosas e continuam a impor uma moral, que parece ser impossível de ser vivida, inclusive no que diz respeitos a afetividade-sexualidade.

A sociedade sempre criou tabus, para expressar afetividade e sexualidade. Tanto que não existe uma única forma de vivenciar e conceber a sexualidade:

Uma constatação inicial poderia abrir nossa discussão: parece que nenhuma sociedade conhecida se satisfaz com os dados anatômicos ou biológicos para definir e afirmar a identidade sexual. Todas, em graus diversos, desenvolvem processos ao mesmo tempo simbólicos, educativos, físicos. que permitem ao mesmo tempo identificar, orientar e até corrigir as marcas da pertença sexual. ${ }^{18}$

$\mathrm{O}$ ambiente em que convivemos socialmente estabelece formas, comportamentos, "estereótipos". O que é ser homem e ser mulher? É útil questionar essa noção de gênero, esse é um aspecto importante, pois quando se fixa nestes estereótipos, como regra imutável, gera-se tensões. Nos auxilia Journet:

${ }^{17}$ VIDAL, M., Ética da sexualidade, p. 39.

18 JOURNET, O., Construir a diferença, p. 26. 
Assim, as representações que constroem a diferença sexual são atravessadas por um duplo movimento: da observação da diferença dos sexos nasce um conjunto de representações, de grades de classificação, que funcionam como categorias cognitivas de cunho bem geral; mas a natureza já é apreendida segundo categorias sociais e ideológicas que a reinterpretam e lhe atribuem valores desiguais. ${ }^{19}$

Analisando o desenrolar da história, pode-se perceber que na Idade Média a sexualidade era pouco vista, falada, e, até mesmo contida. Já na modernidade se vê uma sociedade que extrapola os valores morais propostos pelo cristianismo, pois a liberdade afetiva e sexual é algo a ser experimentado. E, portanto, sofre-se com a banalização e comercialização dessa dimensão tão importante para a constituição do ser humano:

Vive-se em uma mudança de época, e seu nível mais profundo é o cultural. Dissolve-se a concepção integral do ser humano, sua relação com o mundo e com Deus; aqui está precisamente o grande erro das tendências dominantes do último século, que exclui Deus de seu horizonte, falsifica conceitos da realidade e só pode terminar em caminhos equivocados e com receitas destrutivas. Os fenômenos sociais, econômicos e tecnológicos estão na base da profunda vivência do tempo, o qual se concebe fixado no presente, trazendo concepções de inconsistência e instabilidade. Deixa-se de lado a preocupação pelo bem comum para dar lugar a realização imediata dos desejos dos indivíduos, à criação de novos direitos individuais, aos problemas da sexualidade, da família. ${ }^{20}$

Ao falar de sexualidade, uma das primeiras coisas que nos vem à mente é o desejo. Seja o de criar novas relações, seja de evitar relações, isto é, até mesmo de contato genital. Assim nos apresenta a Sagrada Congregação para a Doutrina da Fé: "Os homens do nosso tempo estão cada vez mais persuadidos de que a dignidade e vocação da pessoa humana exigem que, à luz da sua própria inteligência, eles descubram os valores inscritos na sua natureza". ${ }^{21} \mathrm{O}$ desejo e o impulso fazem parte da nossa constituição. E a liberdade de decisão e escolha é que nos dignificam:

\footnotetext{
${ }^{19}$ JOURNET, O., Construir a diferença, p. 32.

${ }^{20}$ DAp 44.

${ }^{21} \mathrm{PH} 3$.
} 
Deus nos criou no bem e para o bem, nosso impulso primordial é para o amor e a comunhão. Não há que entender imediatamente a impulsividade como fonte de atos imorais, violentos. Na concepção cristã, o primeiro impulso se dá na esfera do bem, na esfera da graça. Antes de Deus-Amorcriador ter proibido ao ser humano comer da árvore do conhecimento, prevenindo-o de não pretender tornar-se senhor do bem e do mal (Gn 2,17), estimulou-o a experimentar de todas as outras árvores, dizendo: "podes comer de todas as árvores do jardim" (Gn 2,16), como a dizerlhe: vai viver, e não tenhas vergonha de ser feliz e de cantar a beleza de ser um eterno aprendiz, deixando-se guiar pelos impulsos da vida e da liberdade, dons primeiros da criação. ${ }^{22}$

Contudo, como cristãos, portadores de valores importantes para a construção da sociedade, como a moralidade e a ética, não haverá possibilidade de se aceitarem posturas impulsivas, que beiram o imediatismo, o egoísmo sem limites, que são atitudes "fontes" do erro e, portanto, da desumanização.

Segundo Vidal "a sexualidade desempenha um papel decisivo no desenvolvimento da personalidade do homem. [...] A sexualidade é uma força violenta, porém - per se - não é um a força totalmente informe ou anárquica". ${ }^{23}$

Quando alinhada e integrada, a sexualidade é dinamismo, é impulso que nos faz buscar relações, sair do individualismo, do egoísmo existencial, e nos permite reconhecer a importância do outro na nossa existência. Assim sendo:

É uma força da pessoa para a pessoa. Estando vinculada à pessoa, a sexualidade adquire uma grande maleabilidade e plasticidade. Torna-se tão ampla quanto a própria pessoa. $\mathrm{Na}$ sexualidade, o homem experimenta sua indigência existencial, e na sexualidade o homem vive sua abertura aos outros, abertura mediante a qual é cumulada sua penúria existencial. ${ }^{24}$

O valor do comportamento sexual deve ser julgado pelo significado pessoal que contém, visto que a sexualidade possui em si mesma uma intencionalidade orientada para a realização pessoal. "Há duas formas de projetar a existência: uma própria da mulher e outra característica do homem [...] daí o caráter relativo e absoluto, a um só tempo, do masculino e do

${ }^{22}$ FELLER, V. G., Antropologia teológica, p. 5.

${ }^{23}$ VIDAL, M., Ética da sexualidade, p. 22.

${ }^{24}$ VIDAL, M., Ética da sexualidade, p. 22. 
feminino: duas categorias que se manifestam nos estudos etnológicos da sexualidade". ${ }^{25}$

Se por um lado, o cristianismo prega que a comunhão de pessoas se realiza no matrimônio, segundo João Paulo $\mathrm{II}^{26} \mathrm{o}$ homem e a mulher dão início à família, que está ligada à genealogia da pessoa. Ao afirmarmos que os cônjuges, enquanto pais, são colaboradores de Deus criador na concepção e geração de um novo ser humano, não nos referimos apenas às leis biológicas, mas sim à paternidade e maternidade humana, dádivas de Deus.

A família é uma comunidade de pessoas, a menor célula social e como tal é uma instituição fundamental para a vida de cada sociedade. "O homem e a mulher constituem entre si comunhão íntima de toda a vida, ordenada por sua índole natural ao bem dos cônjuges, à procriação e educação da prole". ${ }^{27}$

Por outro lado, o que se observa em muitos casais é que a perenidade dessa união está abalada. Constata-se no seio do cristianismo muitos casais em segunda união, ou que não sacramentaram sua união, divórcios, filhos fora do casamento, traições... Não discutiremos as razões e as causas dessa realidade, mas o que se constata é que o perfil da família está mudado e nesta mudança fragmentada:

A família apresenta-se, outrossim, como vítima dos que convertem em ídolos o poder, a riqueza, e o sexo. Para isto contribuem as estruturas injustas, sobretudo os meios de comunicação, não só com suas mensagens de sexo, lucro, violência, poder, ostentação, mas pondo em destaque elementos que contribuem para o divórcio, a infidelidade conjugal o aborto ou a aceitação do amor livre e das relações prématrimoniais. ${ }^{28}$

Ao se tratar de família, além das questões acima citadas, o cristianismo precisa dar resposta de acolhimento a outros modelos, como casais homoafetivos, mães e pais solteiros, idosos que se unem sem o matrimônio, casais sem filhos etc. Para isso é preciso abertura, aprimorar o discurso, visto que o ser humano busca sempre amar e foi feito para o bem. Esse tema precisa ser melhor esclarecido, e não é nossa proposta aprofundar ele neste artigo e sim instigar a pensar, pois além de religiosa é uma realidade social e, portanto,

${ }^{25}$ VIDAL, M., Ética da sexualidade, p. 56.

${ }^{26}$ Gratissimam Sane 9.

${ }^{27}$ CEC 1601.

${ }^{28}$ DP 573. 
pastoral. Neste sentido faz-se necessária uma citação da Exortação Apostólica Amoris Laetitia, do Papa Francisco, que expressa:

A este respeito quero lembrar aqui uma coisa que aprendi propor, com clareza, a toda a Igreja para não nos equivocarmos no caminho: "Duas lógicas percorrem toda história da Igreja: marginalizar e reintegrar. (...) O caminho da Igreja, desde o Concílio de Jerusalém em diante, é sempre o de Jesus: o caminho da misericórdia e da integração. (...) O caminho da Igreja é o de não condenar eternamente ninguém; derramar a misericórdia de Deus sobre todas as pessoas que a pedem com o coração sincero. ${ }^{29}$

A formação para o verdadeiro amor é a melhor preparação para a vocação da família. Na família as crianças e os jovens poderão aprender a viver a sexualidade humana com a densidade e no contexto de uma vida cristã. Os pais hoje têm motivos para se preocuparem com a estabilidade do futuro dos filhos. Porém é preciso agir com otimismo, empenhando-se a dar aos filhos uma profunda formação cristã, que os torne capazes de superar as diferentes dificuldades para se tornarem verdadeiramente livres:

$\mathrm{O}$ gesto de uma mulher e um homem se doarem no amor e formarem família é sinal do amor de Deus para com a humanidade. Portanto é sacramento. E o próprio Deus escolheu esse exemplo para falar do seu amor pelo seu povo. Um dos temas centrais da Bíblia é o da Aliança, ou seja, o contrato de amor que Deus quis assinar com o povo, e em Jesus Cristo, com a humanidade inteira. ${ }^{30}$

É no seio familiar que se ama e que vive dignamente, que a pessoa descobre os motivos e o caminho para pertencer à família de Deus. Dela se recebe a vida que é a primeira experiência do amor e da fé. Deus abençoa as famílias, apesar de tantas feridas e divisões, pois são estas feridas que nos mostram caminhos de esperança, de vida nova para ser feliz:

No matrimônio e na família constitui-se um complexo de relações interpessoais, vida conjugal, paternidade-maternidade, filiação, fraternidade; mediante as quais cada pessoa humana é introduzida na "família humana" e na "família de Deus", que é a Igreja. O matrimônio e a família dos cristãos edificam a Igreja: na família, de facto, a pessoa humana não só é gerada e progressivamente introduzida, mediante a

\footnotetext{
${ }^{29}$ AL 296.

${ }^{30}$ BORTOLINI, J., Os sacramentos em sua vida, p. 170.
} 
educação, na comunidade humana, mas mediante a regeneração do batismo e a educação na fé, é introduzida também na família de Deus, que é a Igreja ${ }^{31}$.

No tocante à doutrina Católica Romana do cristianismo, temos a promulgação de dois documentos que buscam dar uma resposta mais evangélica e mais acolhedora às famílias. Seja uma resposta que anima e fortalece as famílias em situação "regular", mostrando que o casamento não é um peso a ser carregado por toda a vida, mas, também, esses documentos querem aproximar-se das famílias em situação "irregular", configuração cada vez mais presente no seio da Igreja. O primeiro documento que inicia este processo é a exortação apostólica Familiaris Consortio, de 1981, escrita pelo Papa João Paulo II e a recente exortação apostólica pós-sinodal Amoris Laetitia, de 2016, do Papa Francisco. Assim é a abertura da Familiaris Consortio:

Consciente de que o matrimônio e a família constituem um dos bens mais preciosos da humanidade, a Igreja quer fazer chegar a sua voz e oferecer a sua ajuda a quem, conhecendo já o valor do matrimônio e da família, procura vivê-lo fielmente, a quem, incerto e ansioso, anda à procura da verdade e a quem está impedido de viver livremente o próprio projeto familiar. Sustentando os primeiros, iluminando os segundos e ajudando os outros, a Igreja oferece o seu serviço a cada homem interessado nos caminhos do matrimónio e da família. ${ }^{32}$

Se analisarmos diferentes culturas e tempos, veremos que as formas de vida comum são diferentes, e assim é possível dizer que há uma superestrutura sociocultural no comportamento sexual. No recente passado ocidental, mesmo quando da parte da família não se dava uma explícita educação sexual, a sociedade, marcada pelo respeito aos valores fundamentais propostos pelo cristianismo, servia objetivamente para proteger e educar seus membros, dando um aspecto homogêneo na vivência social.

$\mathrm{Na}$ atualidade, devido à falta desse modelo, tanto nos países desenvolvidos como naqueles em vias de desenvolvimento, a realidade tem sido outra. Uma sociedade heterogênea, com muitas possibilidades, a moral sexual cristã é apenas mais uma das possibilidades. Sem a educação sexual no seio familiar que oriente a valores e a saudável relação com o outro, a "voz" do cristianismo tem perdido sua eficácia no dia a dia das sociedades. É só numa

\footnotetext{
${ }^{31} \mathrm{FC} 15$.

${ }^{32} \mathrm{FC} 1$.
} 
aproximação de discurso e ações das igrejas cristãs que se alcançará maiores efeitos junto às sociedades:

Há, portanto uma cultura em que a sociedade e os meios de comunicação, na maior parte das vezes, oferecem a esse respeito uma informação despersonalizada, lúcida, muitas vezes pessimista e, além disso, sem consideração pelas diversas etapas de formação e de evolução das crianças e dos jovens, sob o influxo de um distorcido conceito individualista da liberdade e num novo contexto privado de valores fundamentais sobre a vida, sobre o amor humano sobre a família. ${ }^{33}$

Porém, o ser humano é chamado ao amor e ao dom de si mesmo na unidade corpórea-espiritual. Feminilidade e masculinidade são dons complementares. Independente do sexo do indivíduo, a sexualidade humana é parte integrante da capacidade concreta de amor que Deus inscreve no homem e na mulher. E aqui podemos trazer novamente a reflexão, sobremaneira, da atuação pastoral e para a acolhida que o Papa Francisco cita na Amoris Laetitia; ou seja, como integrar e acolher as situações chamadas irregulares, ou ainda a de casais do mesmo sexo, que cada vez mais vem buscando direitos legitimamente legais, perante as leis civis, de adoção, de construir uma célula familiar:

Iluminada pelo olhar de Cristo, a Igreja "dirige-se com amor àqueles que participam na sua vida de modo incompleto, reconhecendo que a graça de Deus também atua nas suas vidas, dando-lhes coragem para fazer o bem, cuidar com amor do outro e estar ao serviço da comunidade onde vivem e trabalham. [...] Embora não cesse jamais de propor a perfeição e convidar a uma resposta mais plena a Deus, "a Igreja deve acompanhar, com atenção e solicitude, os seus filhos mais frágeis, marcados pelo amor ferido e extraviado, dando-lhes confiança e esperança, como a luz do farol de um porto ou de uma tocha acessa no meio do povo para iluminar aqueles que perderam a rota ou estão no meio da tempestade". Não esqueçamos que, muitas vezes, o trabalho da Igreja é semelhante ao de um hospital de campanha. ${ }^{34}$

Ainda assim, com estes dois documentos, não são abordadas as questões referentes às uniões homoafetivas, visto que não são consideradas uniões familiares legítimas. No entanto, seria justo questionar se em uma união de pessoas do mesmo sexo, não há a relação feminilidade e a masculinidade, não

${ }^{33}$ CONSELHO PONTIFÍCIO PARA A FAMÍLIA, Sexualidade humana, 1.

${ }^{34}$ AL 291. 
o masculino e o feminino, mas sim, as características que diferem as relações? Duas pessoas do mesmo sexo, criando uma criança, como a igreja acolhe esta criança no seu seio? Visto que ela não tem culpa alguma da situação que está envolta. Como se posicionar perante a educação cristã destas crianças? Se seus pais/mães desejam permanecer no seio da Igreja, como ajudá-los a se integrar e somar forças juntos a sua comunidade de fé? Poderíamos elencar inúmeras outras perguntas, no entanto sabemos que as respostas que integram e acolhem estão em construção, e que as respostas que temos, ainda são duras e excluem mais do que acolhem.

Assim sendo, trazemos uma citação de Amoris Laetitia que tenta compreender estas situações reflexivas acima citadas:

Temos dificuldades em apresentar o matrimônio mais como um caminho dinâmico de crescimento e realização do que como um fardo a carregar a vida inteira. Também nos custa deixar espaço a consciência dos fiéis, que muitas vezes respondem da melhor forma que podem ao Evangelho no meio dos seus limites e são capazes de realizar o seu próprio discernimento perante situações em que se rompem todos os esquemas. Somos chamados a formar as consciências, não a pretender substituí-las. ${ }^{35}$

A sexualidade é um componente fundamental da personalidade, um modo de ser, de se manifestar, de se comunicar com os outros, de sentir, de expressar e de viver o amor humano e realizar o próprio sentido de existir. Qualquer forma de amor será marcada por esta caracterização masculina e feminina, pois tantos homens como mulheres têm dentro de si vestígios da sexualidade oposta. As relações são compostas por estas caracterizações de masculino e feminino, independente do gênero sexual dos amantes em questão.

Pondo entre aspas "família" e reduzindo a perspectiva ao âmbito da união conjugal, o casamento se integra por meio de dois fatores essenciais: a vida do casal conjugal e a confirmação sociocultural-jurídica. Limitando a consideração à vida do casal e deixando de lado a configuração sociojurídica, constata-se um elemento básico nuclear na realidade viva do casal conjugal: o amor conjugal.

${ }^{35}$ AL 37. 


\section{Conclusão}

Falar sobre sexualidade-afetividade é falar de vida, é falar de sociedade é falar de indivíduos. Não se pode separar as dimensões que constituem o ser humano da sua integridade. O que se buscou foi um esforço de ajudar a entender um pouco mais nosso existir como criaturas de Deus.

Apresentou-se algumas situações que a humanidade enfrentou e enfrenta na problemática da sexualidade. No decorrer da história, o ser humano foi descobrindo um sentido diferente para a sua existência, seu modo de ser, conviver e de agir, e essa descoberta passa necessariamente pela questão afetiva-sexual que interfere em seu comportamento.

Podemos comparar a história com um pêndulo que vai de um extremo a outro e retorna de onde foi lançado até que pare e fique centralizado. Em algumas épocas e situações, o tabu, em outras, a permissividade. Onde estamos nesse processo não se sabe ao certo. Mas é exatamente isso que buscamos: achar um meio termo onde se valorize o corpo, o indivíduo, a união conjugal, as expressões sexuais saudáveis.

E, num segundo momento, buscou-se apresentar o matrimônio cristão. A valorização dos seres, que são distintos, mas que se complementam. Apresentou-se, ainda, a dificuldade que é a vivência e a moral da afetividadesexualidade cristã na atualidade, bem como as dificuldades pastorais para acolhida dos novos modelos familiares que vem surgindo. Assim, também as atualizações pastorais que a raiz Católica Romana do cristianismo vem oferecendo para incluir as pessoas, ditas em situações familiares "irregulares", de uma maneira menos excludente, pautado principalmente no documento Amoris Laetitia do Papa Francisco.

Destacou-se a importância de uma boa formação familiar no âmbito afetivo-sexual. Visto que a sociedade em geral não oferece mais um aporte seguro às crianças e jovens, faz-se necessário que eles saibam enfrentar as adversidades, e tristezas que a vida afetiva-sexual desregrada pode oferecer, e possam optar pela felicidade que é a integração de sua sexualidade.

É preciso ter empatia, amor, cuidado com o outro, afinal as relações afetivos-sexuais vão além das relações genitais, ou das matrimoniais familiares; elas perpassam nosso existir, e nos acompanham no dia a dia no nosso relacionamento com o outro, conosco mesmos, com o que nos cerca e com Deus. 


\section{Referências bibliográficas}

BORTOLINI, J. Os sacramentos em sua vida. São Paulo: Paulus, 2007. BRANDÃO, S. R. Afetividade e sexualidade para o adolescente, 13. jul 2014.

$<$ http://www.pucsp.br/fecultura/textos/amor_humano/afetividade.html $>$. Acesso em: 27 out. 2018.

CATECISMO DA IGREJA CATÓLICA. Petrópolis, RJ: Vozes; São Paulo: Paulinas / Loyola, 1993.

CELAM. Aparecida - texto conclusivo da V Conferência Geral do Episcopado Latino-Americano e do Caribe. CNBB: Brasília; São Paulo: Paulinas / Paulus, 2008.

CELAM. Puebla: a evangelização no presente e no futuro da América Latina. Petrópolis, RJ: Vozes, 1979.

CONGREGAÇÃo PARA A DOUTRINA DA FÉ. Persona Humana Declaração sobre alguns pontos da ética sexual. Petrópolis, RJ: Vozes, 1976.

CONSELHO PONTIFÍCIO PARA A FAMÍLIA. Sexualidade humana: verdade e significado. São Paulo: Paulinas, 1998.

FELLER, V. G. Antropologia teológica. Apostila. Curso Superior de Ciências Religiosas - Agregado a PUC-PR. Florianópolis, SC, 2012. $22 \mathrm{f}$.

FRANCISCO, PP. Exortação Apostólica Pós-Sinodal Amoris Laetitia Sobre o amor na família. São Paulo: Paulinas, 2016.

JOUNET, O. Construir a diferença. In: LACROIX, X. (Org.). Homem e mulher: a inapreensível diferença. Petrópolis: Vozes, 2002. p. 25-33.

JOÃO PAULO II, PP. Gratissimam Sane - Carta às famílias. São Paulo: Paulinas, 1994.

JOÃO PAULO II, PP. Exortação apostólica Familiaris Consortio - sobre a função da família cristã no mundo de hoje. Vaticano, 1981. Disponível em: $<$ https://w2.vatican.va/content/john-paul-

ii/pt/apost_exhortations/documents/hf_jp-ii_exh_19811122_familiarisconsortio. $\overline{h t m l}>$. Acesso em: 22 ago 2020.

LACROIX, X. Introdução. In: LACROIX, X. (Org.). Homem e mulher: a inapreensível diferença. Petrópolis: Vozes, 2002. p. 7-9. 
VIDAL, M. Ética da sexualidade. São Paulo: Loyola, 2002.

Alison Humberto Furlan Mestre em Teologia pela Pontifícia Universidade Católica do Paraná Joinville / SC - Brasil E-mail: iralison@grupomarista.org.br

Recebido em: 26/04/2020

Aprovado em: 06/10/2020 